\title{
Interactions among methylenetetrahydrofolate reductase (MTHFR) and cystathionine $\beta$-synthase (CBS) polymorphisms - a cross-sectional study: multiple heterozygosis as a risk factor for higher homocysteine levels and vaso-occlusive episodes
}

\author{
F.M. Amaral ${ }^{1,2}$, A.L. Miranda-Vilela ${ }^{3}$, G.S. Lordelo ${ }^{2,3}$, I.F. Ribeiro ${ }^{3,4}$, \\ M.B. Daldegan ${ }^{2}$ and C.K. Grisolia ${ }^{3}$ \\ ${ }^{1}$ Fundação Hemocentro de Brasília, Brasília, DF, Brasil \\ ${ }^{2}$ Núcleo de Hematologia e Hemoterapia do Hospital de Base do Distrito Federal, \\ Brasília, DF, Brasil \\ ${ }^{3}$ Instituto de Ciências Biológicas, Departamento de Genética e Morfologia, \\ Universidade de Brasília, Brasília, DF, Brasil \\ ${ }^{4}$ Centro Universitário Unieuro, Brasília, DF, Brasil \\ Corresponding author: C.K. Grisolia \\ E-mail: grisolia@unb.br
}

Genet. Mol. Res. 16 (1): gmr16019374

Received September 23, 2016

Accepted January 23, 2017

Published February 23, 2017

DOI http://dx.doi.org/10.4238/gmr16019374

Copyright $(C 2017$ The Authors. This is an open-access article distributed under the terms of the Creative Commons Attribution ShareAlike (CC BY-SA) 4.0 License.

\begin{abstract}
High plasma homocysteine (Hcy) levels may be responsible for vaso-occlusive episodes and may have acquired and/or genetic causes. This cross-sectional study aimed to investigate the role of methylenetetrahydrofolate reductase (MTHFR; C677T; A1298C) and cystathionine- $\beta$-synthase (CBS; T833C/844ins68, G919A) polymorphisms in serum levels of folic acid, vitamin B12 and Hcy, and to verify a possible association between these polymorphisms and the clinical variability. Blood samples of Brazilian patients with a diagnosis
\end{abstract}

Genetics and Molecular Research 16 (1): gmr16019374 
of thrombosis were submitted to genotyping by PCR-based methods and serum dosages of folic acid, vitamin B12 and Hcy. Except for the CBS G919A polymorphism, all other genetic markers were in HardyWeinberg equilibrium. An increased risk for venous thrombosis was found for the MTHFR $1298 \mathrm{CC}$ carriers $(\mathrm{OR}=1.688 ; 95 \% \mathrm{CI}=0.839$ $3.398, \mathrm{P}=0.018)$ and those homozygously mutant for the CBS haplotype 844ins68/T833C $(\mathrm{OR}=2.488 ; 95 \% \mathrm{CI}=0.501-12.363, \mathrm{P}=0.031)$, while heterozygous for this CBS haplotype showed an increased risk for higher Hcy levels $(\mathrm{OR}=5.900 ; 95 \% \mathrm{CI}=1.003-34.691, \mathrm{P}=0.030)$. Significant interactions were observed among the MTHFR C677T, MTHFR A1298C and CBS haplotype 844ins68/T833C polymorphisms in the results for Hcy levels $(\mathrm{P}=0.000)$, where heterozygous had higher values. Interactions among these polymorphisms can affect serum Hcy levels, where multiple heterozygosis could be a risk factor for vasoocclusive episodes.

Key words: Homocysteine; Thrombosis; Thrombophilia; Multifactorial inheritance; Genetic polymorphisms

\section{INTRODUCTION}

Thrombophilias are defined as a predisposition to venous or arterial thrombosis due to hematological changes inducing blood hypercoagulability. They are individually characterized by wide phenotypic variability, even when they occur within the same family (Miranda-Vilela, 2012). Although hereditary thrombophilias are, in most cases, due to changes related to physiological coagulation, high levels of plasma homocysteine (Hcy) may also be responsible for vaso-occlusive episodes and may have acquired (nutritional deficiencies of vitamin B12, vitamin B6 and folate, advanced age, chronic renal failure and the use of anti-folic drugs) and/or genetic causes; the latter being typically caused by mutations in the genes responsible for expression of enzymes involved in the intracellular metabolism of Hcy - methylenetetrahydrofolate reductase (MTHFR, EC 1.5.1.20) and cystathionine $\beta$-synthase (CBS, EC 4.2.1.22) (Franco, 2001; Papa et al., 2001; Franco and Reitsma, 2001; Guimarães et al., 2009; Chong et al., 2012; Miranda-Vilela, 2012).

Hcy is a sulfhydryl amino acid that has a toxic effect on endothelial cells, impairing generation of nitric oxide and prostacyclin, besides increasing platelet adhesion, activating factor $\mathrm{V}$, inducing tissue factor activity and inhibiting tissue-type plasminogen activator (Previtali et al., 2011). Thus, high levels of plasma Hcy have been proposed as an independent risk factor for both venous and arterial thrombotic diseases (Papa et al., 2001; Varga et al., 2005; Kaul et al., 2006). Although its pathogenesis is complex, since genetic and environmental variables interact to determine plasma levels of Hcy (Franco, 2001; Buchanan et al., 2003; Miranda-Vilela, 2012), inherited or acquired deficiencies in both its remethylation pathway (catalyzed by the enzymes methionine synthase, EC 2.1.1.13, and MTHFR, in a process that uses folate and vitamin B12 as cofactors) and its trans-sulfuration pathway (catalyzed by CBS, which uses vitamin B6 as a cofactor) can result in elevated plasma levels of this amino acid (Miranda-Vilela, 2012).

Several mutations in genes MTHFR and CBS have been identified. Most are rare, with clinical consequences manifesting only in homozygous condition (Franco, 2001; Miranda-

Genetics and Molecular Research 16 (1): gmr16019374 
Vilela, 2012). In contrast to this rarity, two single nucleotide polymorphisms (SNPs) in the MTHFR gene - C677T (dbSNP rs1801133) and A1298C (dbSNP rs1801131) - and in the CBS gene - G919A (dbSNP rs121964962) and T833C (dbSNP rs5742905) -, as well as a 68-bp insert in the CBS gene (844ins68), are prevalent and therefore should be highlighted in venous thromboembolism (VTE) and increased risk of premature artery disease (Franco, 2001; Franco and Reitsma, 2001; Marcucci et al., 2003; Miranda-Vilela, 2012).

The MTHFR gene is located on chromosome 1p36.3, and transition C677T resulting in the substitution of an alanine for a valine is at position 222 (Ala222Val), which causes reduced enzyme activity with thermolabile protein properties; this is the most common genetic abnormality in Hcy metabolism (Blom, 2000; Varga et al., 2005; Miranda-Vilela, 2012; Vuckovic et al., 2013). A second genetic polymorphism in the MTHFR gene (A1298C), resulting in alanine replacing glutamate at position 429 of the enzyme (Glu429Ala), has also been associated with reduced enzymatic activity. However, when it is found alone, it appears not to lead to severe enzyme deficiency nor be associated with hyperhomocysteinemia or reduced plasma folate levels (Blom, 2000; Miranda-Vilela, 2012), although a significant association of the MTHFR A1298C polymorphism (but not of the MTHFR C677T) has been established with ischemic stroke in the Eastern Chinese Han population (Lv et al., 2015). Compound heterozygosity for these two polymorphisms, i.e., individuals with the 677CT/1298AC genotype, has been associated with reduced enzyme activity, decreased plasma folate levels and elevated Hcy (Franco et al., 1999; Blom, 2000; Franco, 2001; Miranda-Vilela, 2012).

The CBS gene is located on chromosome 21q22.3, and the G919A and T833C polymorphisms deserve note for having been identified as prevalent in clinical cases of homocystinuria, a genetic defect associated with severe hyperhomocysteinemia leading to obstructive coronary and peripheral vascular events (Bydlowski et al., 1998; Miranda-Vilela, 2012). The G919A transition results in a serine protein replacing a glycine at position 307 (G307S), while the T833C transition results in threonine substituting isoleucine at codon 278 (I278T). Although CBS homozygous deficiency is rare, heterozygous deficiency is relatively common and leads to moderate elevation of Hcy (Miranda-Vilela, 2012). Additionally, the CBS 844ins68 polymorphism has been found segregating in cis with CBS T833C. Although the insertion alone has been reported not influencing Hcy levels (Franco and Reitsma, 2001; Miranda-Vilela, 2012), its presence in heterozygous has been found with increased frequency among patients with deep vein thrombosis (DVT) (Bonini-Domingos et al., 2005). Moreover, in combination with MTHFR C677T polymorphism it can lead to increased risk of thromboembolic events (Blom, 2000; Franco and Reitsma, 2001; Miranda-Vilela, 2012).

The efficient recognition and management of risk factors for thrombosis are very important for routine clinical treatment and prevention of this disease (Miranda-Vilela, 2012; Vuckovic et al., 2013), taking into account that: 1) thromboses are events of multigenic and multifactorial etiopathology (Miranda-Vilela, 2012); 2) the presence of mutations in several genes significantly increases the risk of their occurrence; and 3) the vascular territory (venous and/or arterial) affected involves different pathophysiological mechanisms and treatments (Miranda-Vilela, 2012).

Albeit frequent in different populations, these polymorphisms have shown great ethnic and geographical variability (Sebastio et al., 1995; Franco et al., 1998; Franco et al., 1999; Dilley et al., 2001; Franco and Reitsma, 2001; Miranda-Vilela, 2012; Antonio-Véjar et al., 2014). As the Brazilian population is very mixed, primarily from five centuries of interethnic

Genetics and Molecular Research 16 (1): gmr16019374 
crosses among Europeans, Africans and Amerindians, and this miscegenation can influence the distribution of certain polymorphisms (Lordelo et al., 2012; Barbosa et al., 2014), the objective of this study was to investigate the role of MTHFR (C677T, A1298C) and CBS (T833C/844ins68, CBS G919A) polymorphisms in serum levels of folic acid, vitamin B12 and Hcy in Brazilian patients with a diagnosis of thrombosis, and to verify a possible association between these polymorphisms and the clinical variability.

\section{MATERIAL AND METHODS}

\section{Study design and participants}

This was a cross-sectional study performed with 85 outpatients of both genders diagnosed with thrombosis, 14-56 years old, in treatment at Hospital de Base do Distrito Federal (HBDF), Brazil from February 2011 to January 2012.

Exclusion criteria comprised patients with deficiency of protein $\mathrm{C}, \mathrm{S}$ or antithrombin activity, resistance to activated protein $\mathrm{C}$, antiphospholipid antibody syndrome (APS), cancer, myeloproliferative diseases, nephrotic syndrome, prolonged immobilization, smoking, and chronic consumption of alcohol or substances affecting homocysteine metabolism (such as anti-folic drugs).

All procedures involving human subjects were approved by the Ethics Committee of the Health State Secretariat of the Federal District, and written informed consent was obtained from all registered volunteers, who were free to withdraw at any time during the study.

\section{Procedures and measurements}

Data were obtained from laboratory tests, questionnaires, medical records and anamnesis. Blood samples collected by venipuncture in Vacutainer tubes containing EDTA were used to carry out genotyping, while serum samples were used for biochemical dosages of folic acid, vitamin B12 and Hcy ( 4 mL/tube).

\section{Biochemical dosages of folic acid, vitamin B12 and Hcy}

Freshly collected serum samples were immediately processed and analyzed by chemiluminescence in Siemens Centaur XP (folic acid, vitamin B12) and Immulite 2000 XPI (Hcy) equipment, using appropriate chemical reagents, controls and manufacturer protocols.

\section{Genotyping of MTHFR C677T, A1298C, and CBS 844ins68, T833C, G919A genetic polymorphisms}

DNA was isolated from the leucocyte fraction by using a Blood genomicPrep Mini Spin Kit (GE Healthcare) purification kit, quantified by a NanoVue ${ }^{\circledR}$ spectrophotometer (GE Healthcare), and amplified in a Veriti ${ }^{\circledR}$ Thermal Cycler (Applied Biosystems).

MTHFR genotyping followed Yi et al. (2002), and CBS genotyping was performed according to Dutta et al. (2005) (844ins68 and CBS T833C), and Song et al. (2006) (G919A) (Table S1). The PCR and the PCR digested products were separated by electrophoresis on $6 \%$ non-denaturing polyacrylamide gels and visualized by staining with silver nitrate.

Genetics and Molecular Research 16 (1): gmr16019374 


\section{Statistical analysis}

The minimum sample size was calculated based on a power analysis from the quantitative data, considering the maximum tolerable sampling error ranging from 0.05 to 0.20 , according to a higher or lower population variability in the reference intervals of the laboratory tests and the samples after stratifications of the total group (Ribeiro et al., 2013; Barbosa et al., 2014).

The genotype distributions were tested for Hardy-Weinberg equilibrium (HWE) by the chi-square $\left(\chi^{2}\right)$ test, using the Genepopweb Statistical Program version 4.1 (http://genepop. curtin.edu.au), where values of $\mathrm{P}>0.05$ were considered to be in HWE. The same program was used to calculate the allelic and genotypic frequencies of each locus, genetic diversity parameters and to test possible linkage disequilibrium between the loci MTHFR and CBS.

For the laboratory tests, statistical analysis was carried out using SPSS (Statistical Package for the Social Sciences) version 17.0. Quantitative variables were first tested for normal distribution with the Shapiro-Wilk test, to choose the most appropriate statistical test for each variable. Data were reported as means \pm standard error, and values of $\mathrm{P}<0.05$ were considered to be statistically significant. Possible differences between genders in serum levels of folic acid, vitamin B12 and Hcy were evaluated by the $t$-test or the Mann-Whitney U test (non-normalized data), while differences in these biochemical parameters among genotypes, age groups and skin color were evaluated by ANOVA or the Kruskal-Wallis test (data not normally distributed), followed respectively by the Bonferroni or Mann-Whitney U tests. Age groups were stratified as: adolescents (14-19 years), young adults (20-40 years) and middleaged (41-56 years) (Freire et al., 2008). Possible correlations between gender/age group, gender/skin color, age group/skin color, gender/genetic polymorphisms, age groups/genetic polymorphisms, skin color/genetic polymorphisms and genetic polymorphisms/comorbidities were analyzed by correlation with the $\chi^{2}$ test. To test correlations between these variables and the dosages of folic acid, vitamin B12 and Hcy, the Spearman correlation test was used, while correlations between two quantitative variables were tested by Pearson (normalized data) or Spearman (data not normally distributed) correlation tests.

Interactions among genetic polymorphisms in the results of serum levels of folic acid, vitamin B12 and Hcy were tested by multivariate analysis of variance (MANOVA), followed by the Tukey post hoc test. To calculate the odds ratio (OR), parameters were considered greater or lesser than the minimum reference limit, which were $3 \mathrm{ng} / \mathrm{mL}$ for folic acid and 150 $\mathrm{pg} / \mathrm{mL}$ for vitamin B12 (Thame et al., 1998); for Hcy the parameter was considered $>12 \mu \mathrm{M}$ (Vuckovic et al., 2013).

\section{RESULTS}

\section{Profile of patient sample}

The sample consisted of 65 females and 20 males: $6(7.1 \%)$ belonging to the age group of 14-19 years (all females), 59 (69.4\%) aged 20-40 years (45 females and 14 males) and $20(23.5 \%)$ aged $41-56$ years (14 females and 6 males). Of these, $32(37.6 \%)$ described themselves as white, $40(47.1 \%)$ as mulatto ("pardo"), and $13(15.3 \%)$ as black. Among the 65 females, 32 were using contraceptives during the event. The general profile of the patient sample is presented in Figure 1.

Genetics and Molecular Research 16 (1): gmr16019374 

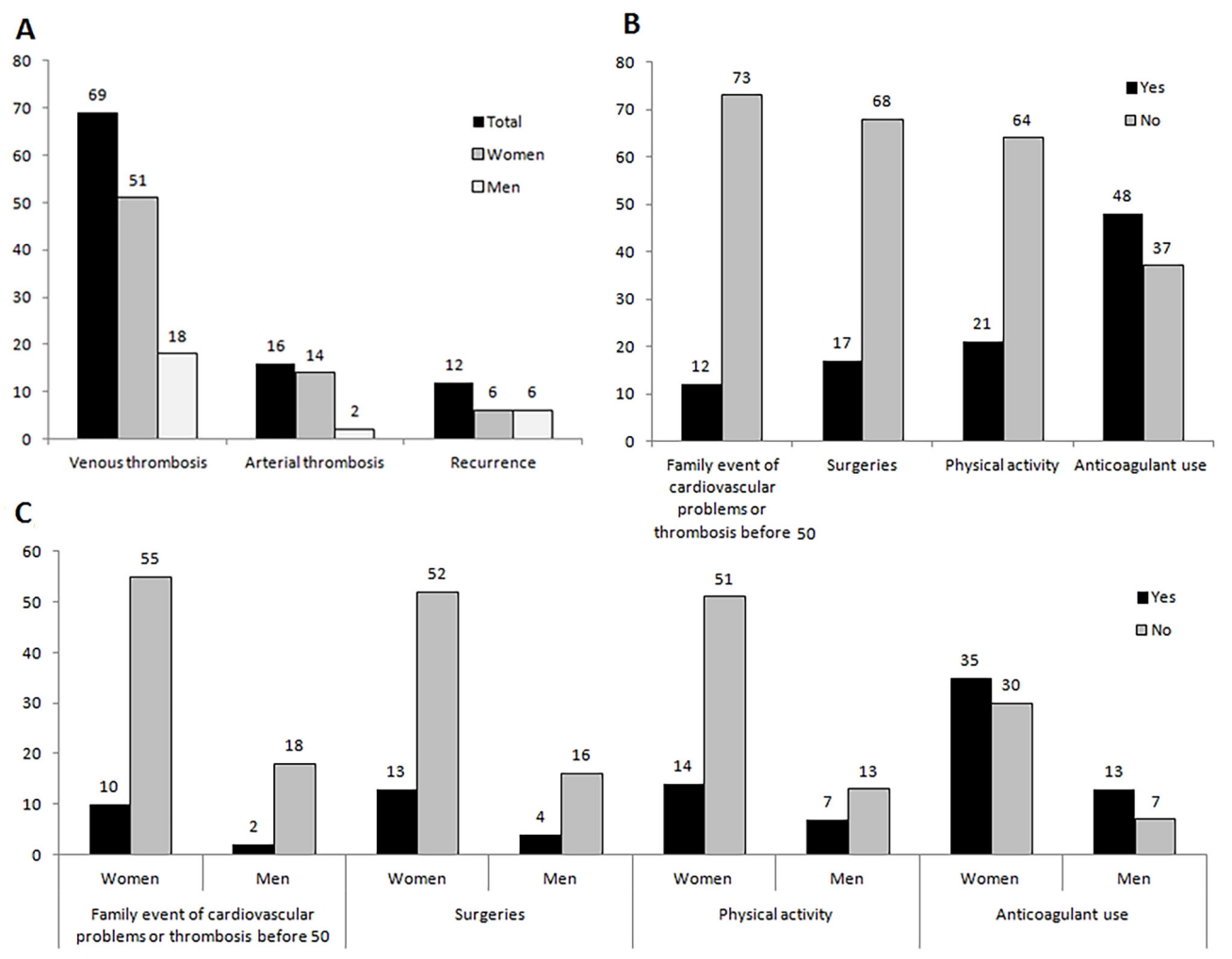

D

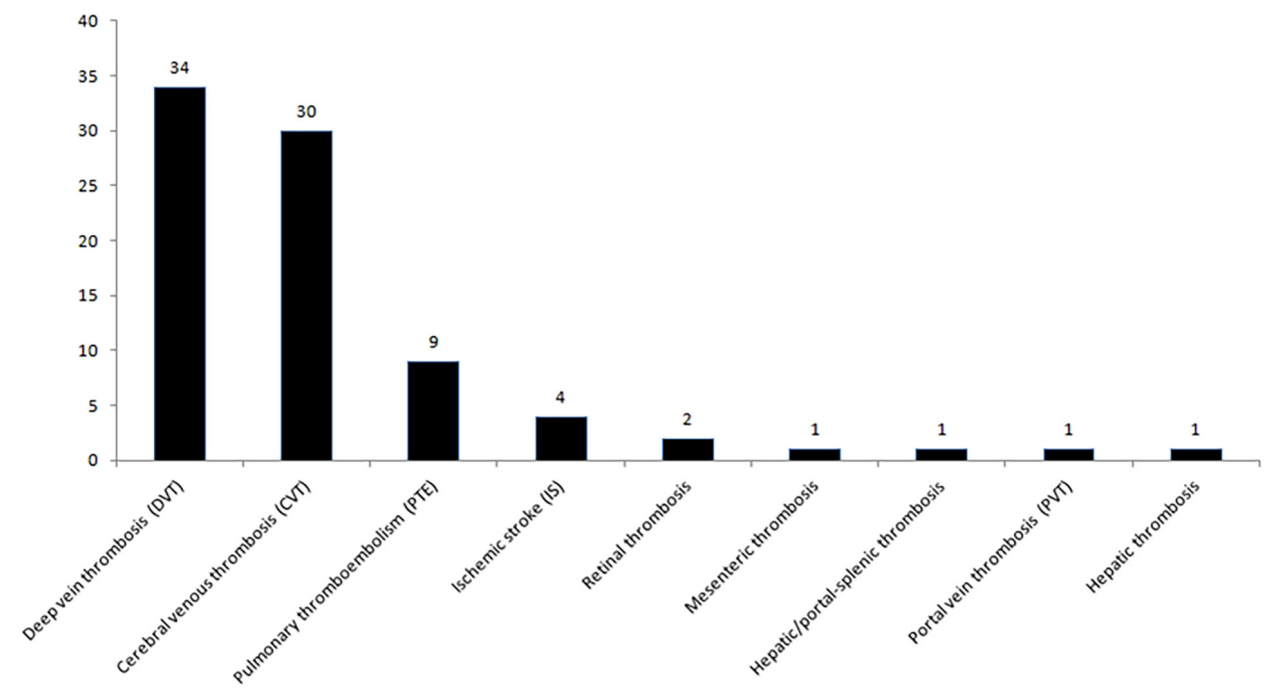

Figure 1. Profile of the patient sample concerning venous thrombosis, arterial thrombosis and recurrence (A); family event of cardiovascular problems or thrombosis before 50, surgeries, physical activity and anticoagulant use for total (B) and gender (C) groups; and comorbidities (D).

Genetics and Molecular Research 16 (1): gmr16019374 


\section{Distribution frequencies and population statistics of MTHFR and CBS polymorphisms}

The genotype distribution of MTHFR C677T and A1298C, and CBS 844ins68 was in accordance with HWE $(\mathrm{P}>0.05)$, while significant deviation from HWE was observed for CBS G919A ( $\mathrm{P}<0.05)$, due to the absence of homozygous mutant AA. Regarding CBS T833C (Dutta et al., 2005), all patients with 68-bp insertion also carried the $\mathrm{C}$ allele (mutant), and its frequency was identical to the I allele of the CBS 844ins68 polymorphism (0.1765). There was a significant linkage disequilibrium only between the loci CBS 844ins68 and CBS G919A $(\mathrm{P}=0.00729)$ (Table 1).

\begin{tabular}{|c|c|c|c|c|c|c|c|c|}
\hline $\begin{array}{l}\text { Genetic } \\
\text { polymorphism }\end{array}$ & $\begin{array}{c}\text { Allele } \\
\text { frequencies }\end{array}$ & Genotypes & $\begin{array}{c}\text { Number of observed } \\
\text { individuals }\end{array}$ & $\begin{array}{l}\text { Number of } \\
\text { expected } \\
\text { individuals }\end{array}$ & $\begin{array}{c}\text { Observed } \\
\text { heterozygosity } \\
\left(H_{\mathrm{O}}\right)\end{array}$ & $\begin{array}{c}\text { Expected } \\
\text { heterozygosity } \\
\left(H_{\mathrm{E}}\right)\end{array}$ & $\begin{array}{c}F_{\text {IS }} \\
\text { (Inbreeding } \\
\text { coefficient) }\end{array}$ & $\begin{array}{l}\text { HWE test } \\
\text { (P values) }\end{array}$ \\
\hline \multicolumn{9}{|l|}{ MTHFR C677T } \\
\hline $\mathrm{C}$ & 0.7294 & $\mathrm{CC}$ & 43 & 45.1243 & & & & \\
\hline \multirow[t]{2}{*}{$\mathrm{T}$} & 0.2706 & $\mathrm{CT}$ & 38 & 33.7515 & 0.4471 & 0.3948 & -0.1267 & 0.2832 \\
\hline & & TT & 4 & 6.1243 & & & & \\
\hline \multicolumn{9}{|l|}{$\begin{array}{l}\text { MTHFR } \\
\text { A1298C }\end{array}$} \\
\hline $\mathrm{A}$ & 0.7412 & AA & 49 & 46.5976 & & & & \\
\hline \multirow[t]{2}{*}{$\mathrm{C}$} & 0.2588 & $\mathrm{AC}$ & 28 & 32.8047 & 0.3294 & 0.3836 & 0.1472 & 0.2602 \\
\hline & & $\mathrm{CC}$ & 8 & 5.5976 & & & & \\
\hline \multicolumn{9}{|l|}{ CBS 844ins68 } \\
\hline $\mathrm{D}$ & 0.8235 & DD & 58 & 57.5740 & \multirow[t]{3}{*}{0.2824} & \multirow[t]{3}{*}{0.2907} & \multirow[t]{3}{*}{0.0345} & \multirow[t]{3}{*}{0.7155} \\
\hline \multirow[t]{2}{*}{ I } & 0.1765 & ID & 24 & 24.8521 & & & & \\
\hline & & II & 3 & 2.5740 & & & & \\
\hline \multicolumn{9}{|l|}{ CBS G919A } \\
\hline $\mathrm{G}$ & 0.7235 & GG & 38 & 44.4934 & \multirow[t]{3}{*}{0.5529} & \multirow[t]{3}{*}{0.4001} & \multirow[t]{3}{*}{-0.3770} & \multirow[t]{3}{*}{0.0002} \\
\hline \multirow[t]{2}{*}{ A } & 0.2765 & GA & 47 & 34.0081 & & & & \\
\hline & & AA & 0 & 6.4984 & & & & \\
\hline
\end{tabular}

P values were generated using statistical program Genepopweb version 4.2 (http://genepop.curtin.edu.au).

\section{Distribution frequencies of MTHFR and CBS polymorphisms in the total group and after stratification by gender, age group and skin color}

For the MTHFR C677T polymorphism, the frequency of the wild genotype (CC) was higher in the total group and females, but heterozygotes predominated in males, while for MTHFR A1298C the wild genotype predominated in both total and gender groups. For the CBS 844ins68 polymorphism, the presence of wild-type allele in homozygous was also more frequent, but for the CBS G919A, there was a predominance of heterozygous genotype (Table 2).

Since all individuals with the insertion of $68 \mathrm{bp}$ in exon 8 of the CBS 844ins68 polymorphism were also carriers of the $\mathrm{C}$ allele (mutant) of the CBS T833C polymorphism, only the data from the CBS 844ins68 polymorphism will be presented throughout this study.

The distribution frequency of genotypes by age group basically followed the same pattern, except for MTHFR C677T, where the range of 14-19 years showed a higher frequency of heterozygotes, although the sample size was only of 6 individuals (Table 3 ). 
Table 2. Distribution of MTHFR C677T, MTHFR A1298C, CBS 844ins68 and CBS G919A genotypes in the patients with thrombophilias by total and gender groups.

\begin{tabular}{l|c|c|c}
\hline Genetic polymorphism & Total group [N (\%)] & Women [N (\%)] & Men [N (\%)] \\
\hline MTHFR C677T & & & $9(10.6)$ \\
\hline CC & $43(50.6)$ & $34(40.0)$ & $10(11.8)$ \\
\hline CT & $38(44.7)$ & $28(32.9)$ & $1(1.2)$ \\
\hline TT & $4(4.7)$ & $3(3.5)$ & $11(12.9)$ \\
\hline MTHFR A1298C & $49(57.6)$ & $38(44.7)$ & $8(9.4)$ \\
\hline AA & $28(32.9)$ & $20(23.5)$ & \\
\hline AC & $8(9.4)$ & $7(8.2)$ & $14(16.4)$ \\
\hline CC & & & $5(5.9)$ \\
\hline CBS 844ins68 & $58(68.2)$ & $44(51.8)$ & $1(1.2)$ \\
\hline DD & $24(28.3)$ & $19(22.4)$ & \\
\hline ID & $3(3.5)$ & $2(2.3)$ & $8(21.1)$ \\
\hline II & $38(44.7)$ & & $12(25.5)$ \\
\hline CBS G919A & $47(55.3)$ & $30(78.9)$ & \\
\hline GG & \multicolumn{2}{|c|}{}
\end{tabular}

Table 3. Distribution of MTHFR C677T, MTHFR A1298C, CBS 844ins68 and CBS G919A genotypes in the patients with thrombophilias by age groups.

\begin{tabular}{l|c|c|c}
\hline \multirow{2}{*}{ Genetic polymorphism } & \multicolumn{3}{|c}{ Age groups (years) } \\
\cline { 2 - 4 } & $14-19[\mathrm{~N}(\%)]$ & $20-40[\mathrm{~N}(\%)]$ & $41-56[\mathrm{~N}(\%)]$ \\
\hline MTHFR C677T & & & $12(14.1)$ \\
\hline CC & $1(1.2)$ & $30(35.3)$ & $6(7.1)$ \\
\hline CT & $4(4.7)$ & $28(32.9)$ & $2(2.3)$ \\
\hline TT & $1(1.2)$ & $1(1.2)$ & $13(15.3)$ \\
\hline MTHFR A1298C & $4(4.7)$ & $32(37.6)$ & $6(7.1)$ \\
\hline AC & $2(2.3)$ & $20(23.5)$ & $1(1.2)$ \\
\hline CC & $0(0.0)$ & $7(8.2)$ & $13(15.3)$ \\
\hline CBS 844ins68 & & & $7(8.2)$ \\
\hline DD & $4(4.7)$ & $41(48.2)$ & $0(0.0)$ \\
\hline ID & $2(2.3)$ & $15(17.6)$ & \\
\hline CBS G919A & $0(0.0)$ & $3(3.5)$ & $7(18.4)$ \\
\hline GG & & & $13(27.7)$ \\
\hline GA & $2(5.3)$ & $29(76.3)$ & \\
\hline
\end{tabular}

Analyzing by skin color, there were higher frequencies of the wild-type genotypes, except for the MTHFR C677T polymorphism, where the CT genotype predominated in mulatto ("pardo"); and for the CBS G919A polymorphism, where the GA genotype predominated in white and black patients (Table 4).

\section{Differences between genders, age group, skin color, and genotypes of MTHFR and CBS in serum levels of folic acid, vitamin B12 and Hcy}

There was a significant difference between genders only for the homocysteine dosage, with higher Hcy levels observed for men (Table 5).

No significant differences in the serum levels of folic acid, vitamin B12 and homocysteine were observed among age groups or skin colors (data not shown). The same was observed for MTHFR and CBS genotypes, although heterozygous for the MTHFR C677T, MTHFR A1298C and CBS 844ins68 polymorphisms had non-significantly higher levels of Hcy than other genotypes (Table 6).

Genetics and Molecular Research 16 (1): gmr16019374 
Table 4. Distribution of CBS 844ins68, CBS G919A, MTHFR C677T and MTHFR A1298C genotypes in the patients with thrombophilias by skin color.

\begin{tabular}{|c|c|c|c|}
\hline \multirow[t]{2}{*}{ Genetic polymorphism } & \multicolumn{3}{|c|}{ Skin color } \\
\hline & White [N (\%)] & Mulatto ("Pardo") [N (\%)] & Black [N (\%)] \\
\hline \multicolumn{4}{|l|}{ MTHFR C677T } \\
\hline $\mathrm{CC}$ & $16(18.8)$ & $16(18.8)$ & $11(12.9)$ \\
\hline $\mathrm{CT}$ & $15(17.6)$ & $21(24.7)$ & $2(2.3)$ \\
\hline TT & $1(1.2)$ & $3(3.5)$ & $0(0.0)$ \\
\hline \multicolumn{4}{|l|}{ MTHFR A1298C } \\
\hline $\mathrm{AA}$ & $17(20.0)$ & $25(29.4)$ & $7(8.2)$ \\
\hline $\mathrm{AC}$ & $12(14.1)$ & $11(12.9)$ & $5(5.9)$ \\
\hline $\mathrm{CC}$ & $3(3.5)$ & $4(4.7)$ & $1(1.2)$ \\
\hline \multicolumn{4}{|l|}{ CBS 844ins68 } \\
\hline $\mathrm{DD}$ & $22(25.9)$ & $28(32.9)$ & $8(9.4)$ \\
\hline ID & $8(9.4)$ & $11(12.9)$ & $5(5.9)$ \\
\hline II & $2(2.3)$ & $1(1.2)$ & $0(0.0)$ \\
\hline \multicolumn{4}{|l|}{ CBS G919A } \\
\hline GG & $10(26.3)$ & $26(68.4)$ & $2(5.3)$ \\
\hline GA & $22(46.8)$ & $14(29.8)$ & $11(23.4)$ \\
\hline
\end{tabular}

Table 5. Serum levels of folic acid, vitamin B12 and homocysteine in the patients with thrombophilias by total and gender groups.

\begin{tabular}{l|c|c|c|c}
\hline Group & $\mathrm{N}(\%)$ & Folic acid $(\mathrm{ng} / \mathrm{mL})$ & Vitamin B12 $(\mathrm{pg} / \mathrm{mL})$ & Homocysteine $(\mu \mathrm{M})$ \\
\hline Total group & $85(100)$ & $10.07 \pm 0.53$ & $471.61 \pm 31.98$ & $8.62 \pm 0.72$ \\
\hline Women & $65(76.5)$ & $10.45 \pm 0.60$ & $433.50 \pm 16.17$ & $7.23 \pm 0.24$ \\
\hline Men & $20(23.5)$ & $8.81 \pm 1.15$ & $600.00 \pm 126.83$ & $13.30 \pm 2.86$ \\
\hline P values & & 0.075 & 0.419 & 0.000 \\
\hline
\end{tabular}

$\mathrm{ng} / \mathrm{mL}=$ nanograms per milliliter; $\mathrm{pg} / \mathrm{mL}=$ picograms per milliliter, $\mu \mathrm{M}=$ micromol per liter. Data are reported as means \pm SE. P values were generated by the Mann-Whitney $U$ test for the comparisons between the genders.

Table 6. Serum levels of folic acid, vitamin B12 and homocysteine in the patients with thrombophilias by the MTHFR C677T, MTHFR A1298C, CBS 844ins68 and CBS G919A genotypes.

\begin{tabular}{l|c|c|c}
\hline & Folic acid $(\mathrm{ng} / \mathrm{mL})$ & Vitamin B12 $(\mathrm{pg} / \mathrm{mL})$ & Homocysteine $(\mu \mathrm{M})$ \\
\hline MTHFR C677T & & & \\
\hline CC & $10.03 \pm 0.63$ & $498.19 \pm 58.95$ & $7.54 \pm 0.28$ \\
\hline CT & $10.22 \pm 0.97$ & $430.08 \pm 23.90$ & $9.89 \pm 1.57$ \\
\hline TT & $9.20 \pm 1.21$ & $576.75 \pm 80.42$ & $0.23 \pm 1.97$ \\
\hline P values & 0.837 & & 0.499 \\
\hline ATHFR A1298C & $9.97 \pm 0.69$ & $448.90 \pm 26.18$ & $8.01 \pm 0.40$ \\
\hline AC & $10.67 \pm 1.05$ & $518.19 \pm 86.42$ & $9.87 \pm 2.10$ \\
\hline CC & $8.64 \pm 1.14$ & $450.75 \pm 38.99$ & $8.08 \pm 0.91$ \\
\hline P values & 0.676 & 0.783 & 0.926 \\
\hline CBS 844ins68 & & & \\
\hline DD & $10.12 \pm 0.69$ & $490.35 \pm 44.48$ & $8.01 \pm 0.34$ \\
\hline ID & $9.90 \pm 0.92$ & $416.52 \pm 29.10$ & $10.31 \pm 2.48$ \\
\hline P values & $10.43 \pm 0.67$ & $538.00 \pm 139.03$ & $7.30 \pm 1.25$ \\
\hline CBS G919A & 0.640 & 0.500 & 0.881 \\
\hline GG & & & $9.2 \pm 1.52$ \\
\hline GA & $9.54 \pm 0.69$ & $447.13 \pm 27.63$ & $0.13 \pm 0.38$ \\
\hline P values & $10.52 \pm 0.8$ & $492.29 \pm 54.34$ & 0.602 \\
\hline
\end{tabular}

$\mathrm{ng} / \mathrm{mL}=$ nanograms per milliliter; $\mathrm{pg} / \mathrm{mL}=$ picograms per milliliter, $\mu \mathrm{mol} / \mathrm{L}=$ micromol per liter. Data are reported as means \pm SE. P values were generated by the Kruskall-Wallis (MTHFR C677T, MTHFR A1298C and CBS 844ins68) or the Mann-Whitney U test (CBS G919A).

Genetics and Molecular Research 16 (1): gmr16019374 


\section{Correlation tests}

No correlation was found between gender/age group, gender/skin color, age group/ skin color, gender/genetic polymorphisms, age group/genetic polymorphisms or skin color/ genetic polymorphism. A positive correlation was detected between gender and Hcy levels $(\mathrm{P}=0.000$, Spearman's correlation coefficient $=0.389)$, where men had higher levels; and between gender and recurrence $\left(\mathrm{P}=0.020 ; \chi^{2}\right.$ contingency coefficient $\left.=0.245\right)$, where there was also a higher recurrence for males.

Regarding the serum levels of folic acid, vitamin B12 and Hcy correlated among themselves; with physical activity and comorbidities, several correlations were also found (Table 7).

Table 7. Serum levels of folic acid, vitamin B12 and homocysteine correlated among themselves, and with physical activity, recurrence and comorbidities.

\begin{tabular}{l|c|c}
\hline & Correlation coefficient & P values \\
\hline Folic acid $v s:$ & & 0.002 \\
\hline Vitamin B12 & 0.339 & 0.022 \\
\hline Homocysteine (Hcy) & -0.252 & 0.038 \\
\hline Physical activity & 0.228 & 0.006 \\
\hline Hcy $v s:$ & 0.299 & 0.035 \\
\hline Recurrence & & 0.000 \\
\hline Physical activity $v s:$ & 0.229 & 0.000 \\
\hline Cerebral venous thrombosis (CVT) & & 0.001 \\
\hline Venous thrombosis $v s:$ & -0.897 & 0.000 \\
\hline Arterial thrombosis & 0.393 & \\
\hline Deep vein thrombosis (DVT) & 0.356 & 0.014 \\
\hline CVT) & -0.461 & 0.000 \\
\hline Ischemic stroke (IS) & & \\
\hline Arterial thrombosis $v s:$ & -0.265 & 0.000 \\
\hline DVT & -0.396 & \\
\hline CVT & 0.414 & 0.001 \\
\hline IS & & \\
\hline Surgery $v s:$ & 0.368 & \\
\hline Retinal thrombosis & & \\
\hline
\end{tabular}

Interaction between MTHFR and CBS polymorphisms in the serum levels of folic acid, vitamin B12 and homocysteine

MANOVA indicated significant interaction among MTHFR C677T, MTHFR A1298C and CBS844ins68 $(\mathrm{P}=0.000)$, and the Tukey post hoc test detected significant differences between the genotypes CC and CT of MTHFR C677T $(\mathrm{P}=0.000)$; AA and AC of MTHFR A1298C $(\mathrm{P}=$ $0.009)$; and DD and ID of CBS844ins68 ( $\mathrm{P}=0.002)$, where all heterozygotes had higher levels.

\section{OR with $95 \%$ confidence intervals (CI)}

A significant association with risk of recurrence was found for men, while decrease in this risk was found for women; physical activity was significantly associated with reduced risk of cerebral venous thrombosis (CVT). An increased risk for venous thrombosis was found for the MTHFR 1298CC carriers and homozygous mutants for the CBS haplotype 844ins68/T833C, while heterozygous for this CBS haplotype showed an increased risk for higher Hcy levels (Table 8). 
Table 8. Odds Ratio (OR) with $95 \%$ confidence interval (CI).

\begin{tabular}{|c|c|c|c|c|}
\hline & Comparisons & $\mathrm{OR}(95 \% \mathrm{CI})$ & P values \\
\hline & & Physical activity and Cerebral venous thrombosis (CVT) & $0.531(0.307-0.919)$ & 0.035 \\
\hline \multirow[t]{2}{*}{ Gender } & Females & Recurrent thrombosis & $0.237(0.066-0.847)$ & 0.020 \\
\hline & Males & Recurrent thrombosis & $4.214(1.180-15.048)$ & 0.020 \\
\hline \multirow{2}{*}{\multicolumn{2}{|c|}{ MTHFR A1298C genotypes }} & $\mathrm{CC}$ and Arterial thrombosis & $0.390(0.170-0.892)$ & 0.049 \\
\hline & & $\mathrm{CC}$ and Venous thrombosis & $1.688(0.839-3.398)$ & 0.018 \\
\hline \multirow{3}{*}{\multicolumn{2}{|c|}{ CBS 844ins68 genotypes }} & DD and Arterial thrombosis & $0.312(0.109-0.898)$ & 0.027 \\
\hline & & ID and Hcy $>12 \mu \mathrm{M}$ & $5.900(1.003-34.691)$ & 0.030 \\
\hline & & II and Venous thrombosis & $2.488(0.501-12.363)$ & 0.031 \\
\hline
\end{tabular}

\section{DISCUSSION}

Cross-sectional studies are advantageous due to their low cost, and there is practically no loss at follow-up. Besides, exposure to the factor or cause is present for the effect at exactly the time or time interval analyzed (Hochman et al., 2005). Although cross-sectional studies are susceptible to selection bias and misclassification, as it is difficult to establish a putative "cause" (Sahebi et al., 2013), this type of study is validated in the scientific literature and is one of the main study designs in classic clinical epidemiology (Hochman et al., 2005; Sahebi et al., 2013). STROBE cross-sectional study guidelines were obeyed in this study, and any potential bias or imprecision, such as the use of a convenience sample and a relatively small sample size, among other minor issues, are discussed below.

Besides being a reference model, serving as a basis for comparison with more realistic models in which evolutionary forces may change allelic frequencies, the HWE adhesion test also evaluates whether chance alone could produce a deviation between observed and expected values (Hartl and Clark, 2010). Since the P values in this study were $>0.05$ for the MTHFR C677T, MTHFR A1298C and CBS 844ins68 polymorphisms, we have no reason to reject the hypothesis that the genotype frequencies of the CBS T833C polymorphism are also in HardyWeinberg proportions, because this polymorphism segregates in cis with 844ins68 in carriers of the insertion (Franco et al., 1998; Dutta et al., 2005; Yakub et al., 2012), corroborating our results. CBS G919A showed a significant deviation from HWE, but that was expected, since in the Brazilian population it seems to be rare, and only the wild-type GG genotype has been reported (Aléssio et al., 2008).

Albeit frequent in different populations, the aforementioned polymorphisms show great ethnic and geographical variability (Sebastio et al., 1995; Franco et al., 1998; Franco et al., 1999; Dilley et al., 2001; Franco and Reitsma, 2001; Miranda-Vilela, 2012). Therefore, it is important to know their frequency in our population and make comparisons with other populations, because our three-hybrid genetic mixture can influence the distribution of certain polymorphisms (Miranda-Vilela et al., 2010; Lordelo et al., 2012; Barbosa et al., 2014).

The MTHFR C677T polymorphism has a high prevalence in the general population, with the frequency of heterozygotes in patients with thrombotic disease ranging between 33.6 and 51.9\% in different ethnic groups (Markus et al., 1997; Morita et al., 1998; Harmon et al., 1999; Lalouschek et al., 1999; Fujimura et al., 2000; Hanson et al., 2001; Lopaciuk et al., 2001; Wu et al., 2001; Zhang and Dai, 2001; Li et al., 2002; Marcucci et al., 2003; He et al., 2010; Alves Jacob et al., 2011). In Brazilian populations of the states of Goiás and Rio de Janeiro, this frequency has been reported around 34\% (Rocha, 2009; Alves Jacob et al., 2011), while in US patients of mixed ancestry with DVT (Hanson et al., 2001), a frequency of $46 \%$ was closer to and homogeneous with that found in our study.

Genetics and Molecular Research 16 (1): gmr16019374 
For MTHFR A1298C, reports involving patients with thrombotic disease are rarer, and heterozygote frequency has been reported varying from 37.4 to $46 \%$ (Franco et al., 1999; Spiroski et al.. 2008; Soltanpour et al., 2011), being the lowest frequency found in Brazilians (37.4\%), especially mulattos ("pardo", 33.3\%) (Franco et al., 1999). Our results corroborate these findings, which showed that the frequency of heterozygotes (33\%) in the total sample of patients varied with skin color and, considering each group separately, were found in $27.5 \%$ of mulattos, $37.5 \%$ of whites and $38.46 \%$ of blacks.

The frequency of CBS 844ins68 in heterozygosity in patients with arterial or venous thrombosis has been reported ranging from 0 to $37.7 \%$, being rare in Native Americans $(0.45 \%)$ and Asians (0-1.1\%), intermediate in Caucasians (13.5-14.5\%) and admixed populations (11.7 $-14.9 \%$ ), and higher in black (37.7\%) (Franco et al., 1998; Tsai et al., 1996, 2000; Zhang and Dai, 2001; Marcucci et al., 2003; Bonini-Domingos et al., 2005). On the other hand, despite the rarity of carriers of the insertion (I) allele reported for Asian patients, both heterozygous (34.48\%) and homozygous (13.79\%) for the mutant $\mathrm{C}$ allele of the CBS T833C polymorphism have been reported in Chinese patients with cerebral thrombosis (Shao et al., 2005). Although apparently contradictory, because of segregation in cis with 844ins68 (Franco et al., 1998; Dutta et al., 2005; Yakub et al., 2012), this may indicate interethnic differences among Asian ethnic groups in this CBS polymorphism, like those observed for African, Afro-American, European, and North American populations (Tsai et al., 1996; Franco et al., 1998; Pepe et al., 1999; Dutta et al., 2005). In our study, the frequency of 844ins68/T833C heterozygotes was $28.2 \%$ in the total sample of patients, and was found in $25 \%$ of white patients, $27.5 \%$ of mulatto patients and $38.5 \%$ of black patients, considering each group separately. Although we did not conduct any studies of ancestry, these results confirm the great influence of our African ancestry even on Caucasian patients. As the population of Brasília is formed by migrants from all regions of Brazil, it tends to reflect the Brazilian population better than any other region (Miranda-Vilela et al., 2009, 2010). Finally, although this study was conducted with a convenience sample, this was composed of patients attended at HBDF, which is a publichealth system center for the diagnosis and treatment of blood disorders in adults in Brazil's Midwest, attending a large geo-economic region (Barbosa et al., 2014). Thus, our sample can be considered as representative of the population under study.

The CBS G919A polymorphism has been reported together with CBS T833C as prevalent in clinical cases of homocystinuria (Hu et al., 1993; Sebastio et al., 1995; MirandaVilela, 2012), but reports on the former in association with mild to moderate elevation of plasma Hcy and/or thrombosis show it to be rare and mostly found among Asian patients (Shao et al., 2005), whose frequencies are different and non-homogeneous with that found in our study. Therefore, our research may provide support not only for more individualized but also more effective treatment for thrombosis patients that do not present deficiency of protein $\mathrm{C}, \mathrm{S}$ or antithrombin activity, resistance to activated protein C, APS or other parameters cited in the exclusion criteria of this study, as discussed below. Acquired or inherited deficiencies in both the Hcy remethylation pathway and trans-sulfuration pathway result in elevated plasma levels of this amino acid (Franco, 2001; Franco and Reitsma, 2001; Marcucci et al., 2003). In the remethylation pathway, MTHFR catalyzes the irreversible conversion of 5,10-methylenetetrahydrofolate to 5-methyltetrahydrofolate, the primary circulatory form of folate, which serves as a methyl donor for Hcy remethylation to methionine (Weisberg et al., 1998; Miranda-Vilela, 2012; Miranda-Vilela and Lordelo, 2013), which in turn is converted to S-adenosylmethionine (SAM) that methylates specific cytosines in DNA, regulating gene

Genetics and Molecular Research 16 (1): gmr16019374 
transcription through methylation (Miranda-Vilela, 2012; Miranda-Vilela and Lordelo, 2013). Thus, higher levels of Hcy have been associated with the presence of the MTHFR C677T polymorphism, which results in thermolability and reduced activity of the MTHFR enzyme (Li et al., 2003). The second polymorphism, A1298C, has been reported as not leading to a severe enzyme deficiency or elevated Hcy when found alone (Blom, 2000; Miranda-Vilela, 2012). However, our OR results showed a 1.7-fold risk for venous thrombosis for MTHFR A1298C, but not for MTHFR C677T. As the A1298C polymorphism lies in the S-adenosylmethionineregulatory domain of the enzyme, folate affects gene expression, regulating cellular SAM levels (Miranda-Vilela, 2012). Since the folate status of our patients was normal (10.12 \pm 4.78), these apparently divergent findings may be partly explained by the small sample size of the MTHFR 1298 CC genotype in this study, and because of this, the large confidence interval, but also by ethnic differences and geographical variability.

CBS is the first key enzyme of the homocysteine trans-sulfuration pathway; it catalyzes the condensation of Hcy with serine to form cystathionine and, ultimately, cysteine (Song et al., 2006; Miranda-Vilela, 2012). Consequently, the mild impairment of enzyme function can affect homocysteine concentration (Song et al., 2006). While homozygous deficiency of CBS is rare, heterozygous deficiency is relatively common and leads to moderate elevation of Hcy (Miranda-Vilela, 2012). Although CBS 844ins68 alone has been reported as not seeming to influence Hcy levels (Franco and Reitsma, 2001), our OR results showed a 5.9-fold risk for Hcy levels greater than $12 \mu \mathrm{M}$ for patients heterozygous (ID) for the insertion. Albeit apparently contradictory, these results corroborate previous association between the CBS T833C heterozygous carriers affecting Hcy concentration (Kelly et al., 2003). Moreover, CBS 844 ins68 in heterozygosity has been found with increased frequency among patients with DVT, suggested a probable risk factor for developing the disease (Bonini-Domingos et al. 2005) and, corroborating this, our results showed a 2.49-fold risk for venous thrombosis for patients homozygous for the insertion (II). However, due to the low frequency of the mutant I allele and, thus, the small sample size mainly of homozygous carriers and consequently the large confidence intervals, these need to be further investigated.

On the other hand, although there were no significant differences in the serum levels of Hcy among the MTHFR and CBS genotypes when analyzed alone, the interactions among MTHFR C677T, MTHFR A1298C and CBS844ins68 polymorphisms were significant, corroborating the multifactorial phenotype of the thrombosis (Chan et al., 2008; Guimarães et al., 2009; Miranda-Vilela, 2012), where each gene locus has a small but consistent contribution, and different mutations in different genes interact with each other and with environmental factors to cause the event. Hcy levels in the inherited hypercoagulable phenotypes are a good example of the challenges faced, as discussed below.

It has been reported that CBS 844ins68 in combination with MTHFR C677T may result in increased risk of thrombosis (Blom, 2000; Franco and Reitsma, 2001; MirandaVilela, 2012). Our results corroborate these findings, adding the MTHFR A1298C contribution in this regard. Since 1) studies which jointly assess the CBS 844ins68 and MTHFR C677T polymorphisms in patients with thrombotic disease are rare (Zhang and Dai, 2001; Marcucci et al., 2003; Alves Jacob et al., 2011); 2) studies which jointly evaluate the MTHFR C677T and A1298C polymorphisms in these patients are still rarer (Hanson et al., 2001); and 3) there are no studies jointly evaluating the influence of MTHFR C677T, MTHFR A1298C, CBS 844ins68/T833C and CBS G919A on serum levels of folic acid, vitamin B12 and Hcy, our study is unprecedented and can help to better understand the role of these polymorphisms as

Genetics and Molecular Research 16 (1): gmr16019374 
a risk factor for the manifestation of thrombotic events. Interactions among MTHFR C677T, MTHFR A1298C and the haplotype 844ins68/T833C achieved significant results for Hcy values, confirming the importance of genetic influences as determinants of Hcy levels (Tsai et al., 2000), where interactions among these polymorphisms may affect serum levels of Hcy, and multiple heterozygosis may be a risk factor indicator for vaso-occlusive episodes. Although the sample size of variant homozygous for each polymorphism was very small and no variant homozygous for the three polymorphisms were detected, this suggestion is still supported by the fact that a single patient who presented the heterozygosis for the three loci had elevated serum Hcy values $(63.6 \mu \mathrm{M})$ (data not shown).

Clinically, hereditary thrombophilia usually manifests with: a) increased predisposition to recurrent thrombosis; b) family history of thrombotic events; c) early occurrence (before 50 years old); d) migration or diffuse thrombosis or unusual site, e) disproportionately severe thrombotic event in relation to the triggering stimulus (Franco, 2001; Franco and Reitsma, 2001; D'Amico, 2003; Guimarães et al., 2009). Also, surgery is one of the classical risk factors for VTE (Franco and Reitsma, 2001), while physical activity decreases it (van Stralen et al., 2007). Because thrombophilic defects can cause various obstetric complications, such as difficulty in getting pregnant, complicated pregnancies, fetal growth retardation, abortions and fetal loss (D'Amico, 2003), and use of oral contraceptives is one of the classical risk factors for VTE (Franco and Reitsma, 2001), the profile of the sample was also investigated in these respects.

Our study also showed influence of gender on Hcy levels, where values were significantly higher in men, even with a much smaller sample size than that of women, where contributions to this variation may be plasma cobalamin, creatinine and fat-free mass and estradiol (Dierkes et al., 2001). Although our research did not measure these, our results were consistent with those seen in other studies in which the dosage of Hcy was higher in men than in women (Dierkes et al., 2001; Jacques et al., 2001; Ardawi et al., 2002; Ganji and Kafai, 2003, 2006). Also, although the sample size of men was much smaller than those of women, results corroborate findings of increased risk of recurrent thrombosis for males (Christiansen et al., 2010), indicating that this risk may be associated with increased Hcy for men.

On the other hand, our sample presented more women than men with thrombosis. Since the family event of thrombosis before 50 years old, physical activity and surgeries were comparatively smaller in women than in men, this could be explained not only by environmental risk factors such as contraceptive use, but also by the fact that women are more likely than men to develop DVT. Indeed, this is a risk that increases with age (Goldstein et al., 2008), since $69.4 \%$ of women belonged to the age-group of $20-40$ years, and $23.5 \%$ to the age group of 41-56 years. As genetics also plays an important role, it is important to remember that this study was performed with 65 females and 20 males. So, the significant results of the interactions among the MTHFR C677T, MTHFR A1298C polymorphisms and the haplotype 844ins68/T833C in the Hcy levels could depend mainly on females. This could also indicate that reference values of Hcy levels in the thrombosis risk events should be revised, mainly for those women with environmental risk factors (and particularly for those heterozygous for these polymorphisms).

While the assessed constitutional factors exhibit association with thrombotic process, physical activity can reduce the risk of venous thrombosis (van Stralen et al., 2007), corroborating our findings of a significant reduction in the risk of thrombosis with physical activity for patients with CVT.

Arterial and venous thromboses have traditionally been viewed as distinct conditions,

Genetics and Molecular Research 16 (1): gmr16019374 
with differences in risk factors, pathology and treatment (Lowe, 2008; Previtali et al., 2011). So, the inverse correlations obtained in this study with venous and arterial thrombosis were expected. The positive correlation between surgery and retinal thrombosis also corroborates the literature, since retinal vein occlusion has been reported as a rare complication after anesthesia and surgery (Grover and Jangra, 2012), and its pathophysiology is related to the development of a thrombotic occlusion (Wong and Scott, 2011).

\section{CONCLUSION}

In conclusion, thromboses are events of multigenic and multifactorial etiopathogenesis, where the risk of disease manifestation associated with each single genetic alteration is relatively low, but the presence of mutations in several genes significantly increases this risk. Our results indicated that interactions among the MTHFR C677T, MTHFR A1298C and CBS haplotype 844ins68/T833C can affect serum levels of Hcy, where multiple heterozygosis could be a risk factor for vaso-occlusive episodes.

\section{Conflicts of interest}

The authors declare no conflict of interest.

\section{ACKNOWLEDGMENTS}

The authors gratefully acknowledge the subjects who participated in this research, the Hematology and Hemotherapy Service of the Hospital de Base do Distrito Federal (HBDF), the Sabin Institute/Sabin Laboratories for technical support in the biochemical dosages and the Foundation to Support Research in the Federal District (FAPDF) for financial support.

\section{REFERENCES}

Aléssio ACM, Siqueira LH, Bydlowski SP, Höehr NF, et al. (2008). Polymorphisms in the CBS gene and homocysteine, folate and vitamin B12 levels: association with polymorphisms in the MTHFR and MTRR genes in Brazilian children. Am. J. Med. Genet. A. 146A: 2598-2602. http://dx.doi.org/10.1002/ajmg.a.32496

Antonio-Véjar V, Del Moral-Hernández O, Alarcón-Romero LC, Flores-Alfaro E, et al. (2014). Ethnic variation of the C677T and A1298C polymorphisms in the methylenetetrahydrofolate-reductase (MTHFR) gene in southwestern Mexico. Genet. Mol. Res. 13: 7950-7957.http://dx.doi.org/10.4238/2014.September.29.8

Ardawi MS, Rouzi AA, Qari MH, Dahlawi FM, et al. (2002). Influence of age, sex, folate and vitamin B12 status on plasma homocysteine in Saudis. Saudi Med. J. 23: 959-968.

Barbosa LCP, Miranda-Vilela AL, Hiragi CdeO, Ribeiro IF, et al. (2014). Haptoglobin and myeloperoxidase (- G463A) gene polymorphisms in Brazilian sickle cell patients with and without secondary iron overload. Blood Cells Mol. Dis. 52: 95-107. http://dx.doi.org/10.1016/.j.bcmd.2013.10.001

Blom HJ (2000). Genetic determinants of hyperhomocysteinaemia: the roles of cystathionine beta-synthase and 5,10-methylenetetrahydrofolate reductase. Eur. J. Pediatr. 159 (Suppl 3): S208-S212.http://dx.doi.org/10.1007/ PL00014405

Bonini-Domingos CR, Zamaro PJA, Mendiburu CF, Sanches FE, et al. (2005). Freqüência da mutação 844 ins68 do gene da cistationina b-sintetase em pacientes com trombose venosa profunda. Rev. Bras. Hematol. Hemoter. 27: 12-15. http://dx.doi.org/10.1590/S1516-84842005000100005

Buchanan GS, Rodgers GM and Ware Branch D (2003). The inherited thrombophilias: genetics, epidemiology, and laboratory evaluation. Best Pract. Res. Clin. Obstet. Gynaecol. 17: 397-411. http://dx.doi.org/10.1016/S1521$\underline{6934(03) 00010-5}$

Genetics and Molecular Research 16 (1): gmr16019374 
Bydlowski SP, Magnanelli AC and Chamone DdeA (1998). Hiper-homocisteinemia e doenças vaso-oclusivas. Arq. Bras. Cardiol. 71: 69-76. http://dx.doi.org/10.1590/S0066-782X1998000700013

Chan MY, Andreotti F and Becker RC (2008). Hypercoagulable states in cardiovascular disease. Circulation 118: 22862297.http://dx.doi.org/10.1161/CIRCULATIONAHA.108.778837

Chong L-Y, Fenu E, Stansby G and Hodgkinson S; Guideline Development Group (2012). Management of venous thromboembolic diseases and the role of thrombophilia testing: summary of NICE guidance. BMJ 344: e3979. http:// dx.doi.org/10.1136/bmj.e3979

Christiansen SC, Lijfering WM, Helmerhorst FM, Rosendaal FR, et al. (2010). Sex difference in risk of recurrent venous thrombosis and the risk profile for a second event. J. Thromb. Haemost. 8: 2159-2168. http://dx.doi.org/10.1111/ j.1538-7836.2010.03994.x

D’Amico EA (2003). Trombofilia: quando suspeitar e como investigar? Rev. Assoc. Med. Bras. 49: 7-8. http://dx.doi. org $/ 10.1590 / \mathrm{S} 0104-42302003000100012$

Dierkes J, Jeckel A, Ambrosch A, Westphal S, et al. (2001). Factors explaining the difference of total homocysteine between men and women in the European Investigation Into Cancer and Nutrition Potsdam study. Metabolism 50: 640-645. http://dx.doi.org/10.1053/meta.2001.23286

Dilley A, Hooper WC, El-Jamil M, Renshaw M, et al. (2001). Mutations in the genes regulating methylene tetrahydrofolate reductase (MTHFR C-->T677) and cystathione b-synthase (CBS G-->A919, CBS T-->c833) are not associated with myocardial infarction in African Americans. Thromb. Res. 103: 109-115. http://dx.doi.org/10.1016/S0049$\underline{3848(01) 00278-X}$

Dutta S, Sinha S, Chattopadhyay A, Gangopadhyay PK, et al. (2005). Cystathionine beta-synthase T833C/844INS68 polymorphism: a family-based study on mentally retarded children. Behav. Brain Funct. 1: 25. http://dx.doi. org/10.1186/1744-9081-1-25

Franco RF (2001). Trombofilias Hereditárias. Medicina (B. Aires) 34: 248-257.

Franco RF and Reitsma PH (2001). Genetic risk factors of venous thrombosis. Hum. Genet. 109: 369-384. http://dx.doi. org/10.1007/s004390100593

Franco RF, Elion J, Lavinha J, Krishnamoorthy R, et al. (1998). Heterogeneous ethnic distribution of the 844 ins 68 in the cystathionine beta-synthase gene. Hum. Hered. 48: 338-342.http://dx.doi.org/10.1159/000022826

Franco RF, Morelli V, Lourenço D, Maffei FH, et al. (1999). A second mutation in the methylenetetrahydrofolate reductase gene and the risk of venous thrombotic disease. Br. J. Haematol. 105: 556-559. http://dx.doi.org/10.1111/j.13652141.1999.01254.x

Freire LMD, Sodré FL, Oliveira RA, Castilho LN, et al. (2008). Controle de qualidade laboratorial pré-analítico: avaliação de solicitações médicas de exames bioquímicos no Hospital de Clínicas da Universidade Estadual de Campinas, São Paulo, Brasil. Rev. Bras. Anal. Clin. 40: 143-145.

Fujimura H, Kawasaki T, Sakata T, Ariyoshi H, et al.(2000). Common C677T polymorphism in the methylenetetrahydrofolate reductase gene increases the risk for deep vein thrombosis in patients with predisposition of thrombophilia. Thromb. Res. 98: 1-8. http://dx.doi.org/10.1016/S0049-3848(99)00231-5

Ganji V and Kafai MR (2006). Population reference values for plasma total homocysteine concentrations in US adults after the fortification of cereals with folic acid. Am. J. Clin. Nutr. 84: 989-994.

Ganji V and Kafai MR; Third National Health and Nutrition Examination Survey (2003). Demographic, health, lifestyle, and blood vitamin determinants of serum total homocysteine concentrations in the third National Health and Nutrition Examination Survey, 1988-1994. Am. J. Clin. Nutr. 77: 826-833.

Goldstein MA, Goldstein MC and Credit LP (2008). Your best medicine: from conventional and complementary medicine - Expert-endorsed therapeutic solutions to relieve symptoms and speed healing. Rodale books, New York.

Grover V and Jangra K (2012). Perioperative vision loss: A complication to watch out. J. Anaesthesiol. Clin. Pharmacol. 28: 11-16. http://dx.doi.org/10.4103/0970-9185.92427

Guimarães SP, Soares JBB, Oliveira VC, Pardini VC, et al. (2009). Mutações predisponentes à trombofilia em indivíduos de Minas Gerais - Brasil com suspeita clínica de trombose. Rev. Bras. Hematol. Hemoter. 31: 19-24. http://dx.doi. org/10.1590/S1516-84842009005000004

Hanson NQ, Aras O, Yang F and Tsai MY (2001). C677T and A1298C polymorphisms of the methylenetetrahydrofolate reductase gene: incidence and effect of combined genotypes on plasma fasting and post-methionine load homocysteine in vascular disease. Clin. Chem. 47: 661-666.

Harmon DL, Doyle RM, Meleady R, Doyle M, et al. (1999). Genetic analysis of the thermolabile variant of 5, 10-methylenetetrahydrofolate reductase as a risk factor for ischemic stroke. Arterioscler. Thromb. Vasc. Biol. 19: 208-211.http://dx.doi.org/10.1161/01.ATV.19.2.208

Hartl DL and Clark AG (2010). Princípios de Genética de Populações., 4th edn. Artmed, Porto Alegre.

Genetics and Molecular Research 16 (1): gmr16019374 
He JA, Hu XH, Fan YY, Yang J, et al. (2010). Hyperhomocysteinaemia, low folate concentrations and methylene tetrahydrofolate reductase C677T mutation in acute mesenteric venous thrombosis. Eur. J. Vasc. Endovasc. Surg. 39: 508-513.http://dx.doi.org/10.1016/j.ejvs.2009.09.014

Hochman B, Nahas FX, Oliveira Filho RS and Ferreira LM (2005). Research designs. Acta Cir. Bras. 20 (Suppl 2): 2-9.

Hu FL, Gu Z, Kozich V, Kraus JP, et al. (1993). Molecular basis of cystathionine b-synthase deficiency in pyridoxine responsive and nonresponsive homocystinuria. Hum. Mol. Genet. 2: 1857-1860. http://dx.doi.org/10.1093/ $\underline{\mathrm{hmg} / 2.11 .1857}$

Alves Jacob M, da Cunha Bastos C and Regina Bonini-Domingos C (2011). The 844ins68 cystathionine beta-synthase and C677T MTHFR gene polymorphism and the vaso-occlusive event risk in sickle cell disease. Arch. Med. Sci. 7: 97-101.http://dx.doi.org/10.5114/aoms.2011.20611

Jacques PF, Bostom AG, Wilson PW, Rich S, et al. (2001). Determinants of plasma total homocysteine concentration in the Framingham Offspring cohort. Am. J. Clin. Nutr. 73: 613-621.

Kaul S, Zadeh AA and Shah PK (2006). Homocysteine hypothesis for atherothrombotic cardiovascular disease: not validated. J. Am. Coll. Cardiol. 48: 914-923. http://dx.doi.org/10.1016/j.jacc.2006.04.086

Kelly PJ, Furie KL, Kistler JP, Barron M, et al. (2003). Stroke in young patients with hyperhomocysteinemia due to cystathionine beta-synthase deficiency. Neurology 60: 275-279. http://dx.doi.org/10.1212/01. WNL.0000042479.55406.B3

Lalouschek W, Aull S, Serles W, Schnider P, et al. (1999). C677T MTHFR mutation and factor V Leiden mutation in patients with TIA/minor stroke: a case-control study. Thromb. Res. 93: 61-69. http://dx.doi.org/10.1016/S0049$\underline{3848(98) 00154-6}$

Li C, Zhang C, Qiu S, Lu X, et al. (2002). Polymorphisms of ACE-1 and MTHFR genes and genetic susceptibility of ischemic stroke. Zhonghua Yi Xue Za Zhi (Taipei) 82: 1046-1049.

Li Z, Sun L, Zhang H, Liao Y, et al.; Multicenter Case-Control Study in China (2003). Elevated plasma homocysteine was associated with hemorrhagic and ischemic stroke, but methylenetetrahydrofolate reductase gene C677T polymorphism was a risk factor for thrombotic stroke: a Multicenter Case-Control Study in China. Stroke 34: 20852090. http://dx.doi.org/10.1161/01.STR.0000086753.00555.0D

Lopaciuk S, Bykowska K, Kwiecinski H, Mickielewicz A, et al. (2001). Factor V Leiden, prothrombin gene G20210A variant, and methylenetetrahydrofolate reductase C677T genotype in young adults with ischemic stroke. Clin. Appl. Thromb. Hemost. 7: 346-350. http://dx.doi.org/10.1177/107602960100700418

Lordelo GS, Miranda-Vilela AL, Akimoto AK, Alves PC, et al. (2012). Association between methylene tetrahydrofolate reductase and glutathione S-transferase M1 gene polymorphisms and chronic myeloid leukemia in a Brazilian population. Genet. Mol. Res. 11: 1013-1026.http://dx.doi.org/10.4238/2012.April.19.6

Lowe GDO (2008). Common risk factors for both arterial and venous thrombosis. Br. J. Haematol. 140: 488-495. http:// dx.doi.org/10.1111/j.1365-2141.2007.06973.x

Lv Q-Q, Lu J, Sun H and Zhang J-S (2015). Association of methylenetetrahydrofolate reductase (MTHFR) gene polymorphism with ischemic stroke in the Eastern Chinese Han population. Genet. Mol. Res. 14: 4161-4168. http:// dx.doi.org/10.4238/2015.April.27.31

Marcucci R, Giusti B, Betti I, Evangelisti L, et al. (2003). Genetic determinants of fasting and post-methionine hyperhomocysteinemia in patients with retinal vein occlusion. Thromb. Res. 110: 7-12. http://dx.doi.org/10.1016/ $\underline{\text { S0049-3848(03)00293-7 }}$

Markus HS, Ali N, Swaminathan R, Sankaralingam A, et al. (1997). A common polymorphism in the methylenetetrahydrofolate reductase gene, homocysteine, and ischemic cerebrovascular disease. Stroke 28: 17391743. http://dx.doi.org/10.1161/01.STR.28.9.1739

Miranda-Vilela AL (2012). Role of polymorphisms in factor V (FV Leiden), prothrombin, plasminogen activator inhibitor type-1 (PAI-1), methylenetetrahydrofolate reductase (MTHFR) and cystathionine b-synthase (CBS) genes as risk factors for thrombophilias. Mini Rev. Med. Chem. 12: 997-1006. http://dx.doi.org/10.2174/138955712802762338

Miranda-Vilela AL, Akimoto AK, Alves PC, Hiragi CO, et al. (2009). Haptoglobin gene subtypes in three Brazilian population groups of different ethnicities. Genet. Mol. Biol. 32: 456-461. http://dx.doi.org/10.1590/S1415$\underline{47572009005000051}$

Miranda-Vilela AL, Alves PC, Akimoto AK, Pereira LC, et al. (2010). The effect of hydrogen peroxide-induced oxidative stress on leukocytes depends on age and physical training in healthy human subjects carrying the same genotypes of antioxidant enzymes' gene polymorphisms. Am. J. Hum. Biol. 22: 807-812.http://dx.doi.org/10.1002/ajhb.21086

Miranda-Vilela AL and Lordelo GS (2013). Role of methylenetetrahydrofolate reductase (MTHFR), glutathione S-transferases (GSTs M1 and T1) and haptoglobin (Hp) gene polymorphisms in susceptibility to Chronic Myeloid Leukemia (CML). J. Hematol. Thromb. Dis. 1:103 (101-116).

Genetics and Molecular Research 16 (1): gmr16019374 
Morita H, Kurihara H, Tsubaki S, Sugiyama T, et al. (1998). Methylenetetrahydrofolate reductase gene polymorphism and ischemic stroke in Japanese. Arterioscler. Thromb. Vasc. Biol. 18: 1465-1469. http://dx.doi.org/10.1161/01. $\underline{\text { ATV.18.9.1465 }}$

Papa A, De Stefano V, Danese S, Chiusolo P, et al. (2001). Hyperhomocysteinemia and prevalence of polymorphisms of homocysteine metabolism-related enzymes in patients with inflammatory bowel disease. Am. J. Gastroenterol. 96: 2677-2682.http://dx.doi.org/10.1111/j.1572-0241.2001.04127.x

Pepe G, Vanegas OC, Rickards O, Giusti B, et al. (1999). World distribution of the T833C/844INS68 CBS in cis double mutation: a reliable anthropological marker. Hum. Genet. 104: 126-129. http://dx.doi.org/10.1007/s004390050924

Previtali E, Bucciarelli P, Passamonti SM and Martinelli I (2011). Risk factors for venous and arterial thrombosis. Blood Transfus. 9: 120-138.

Ribeiro IF, Miranda-Vilela AL, Klautau-Guimarães MdeN and Grisolia CK (2013). The influence of erythropoietin (EPO T $(\mathrm{G})$ and a-actinin-3 (ACTN3 R577X) polymorphisms on runners' responses to the dietary ingestion of antioxidant supplementation based on pequi oil (Caryocar brasiliense Camb.): a before-after study. J. Nutrigenet. Nutrigenomics 6: 283-304.http://dx.doi.org/10.1159/000357947

Rocha VR (2009). Perfil de trombofilias hereditárias em pacientes com distúrbios trombóticos em uso de anticoagulante oral. Rev. Bras. Hematol. Hemoter. 31: 487-488. http://dx.doi.org/10.1590/S1516-84842009000600023

Sahebi L, Dastgiri S, Ansarin K, Sahebi R, et al. (2013). Study designs in genetic epidemiology. ISRN Genetics: ID 952518: 8 pages.

Sebastio G, Sperandeo MP, Panico M, de Franchis R, et al. (1995). The molecular basis of homocystinuria due to cystathionine beta-synthase deficiency in Italian families, and report of four novel mutations. Am. J. Hum. Genet. 56: 1324-1333.

Shao Y, Zhang CG and Cui JH (2005). Association of plasma homocysteine and cystathionine beta-synthase polymorphism with cerebral thrombosis. J. First Mil. Med. Univ. 25: 351-353.

Soltanpour MS, Soheili Z, Pourfathollah AA, Samiei S, et al. (2011). The A1298C Mutation in Methylenetetrahydrofolate Reductase Gene and Its Association With Idiopathic Venous Thrombosis in an Iranian Population. Lab. Med. 42: 213-216. http://dx.doi.org/10.1309/LM5LWXCHVZY9RFOM

Song XM, Zheng XY, Zhu WL, Huang L, et al. (2006). Relationship between polymorphism of cystathionine beta synthase gene and congenital heart disease in Chinese nuclear families. Biomed. Environ. Sci. 19: 452-456.

Spiroski I, Kedev S, Antov S, Arsov T, et al. (2008). Methylenetetrahydrofolate reductase (MTHFR-677 and MTHFR-1298) genotypes and haplotypes and plasma homocysteine levels in patients with occlusive artery disease and deep venous thrombosis. Acta Biochim. Pol. 55: 587-594.

Thame G, Shinohara EMG, Santos HGD and Moron AF (1998). Folato, vitamina B12 e ferritina sérica e defeitos do tubo neural. Rev. Bras. Ginecol. Obstet. 20: 449-453. http://dx.doi.org/10.1590/S0100-72031998000800004

Tsai MY, Bignell M, Schwichtenberg K and Hanson NQ (1996). High prevalence of a mutation in the cystathionine betasynthase gene. Am. J. Hum. Genet. 59: 1262-1267.

Tsai MY, Bignell M, Yang F, Welge BG, et al. (2000). Polygenic influence on plasma homocysteine: association of two prevalent mutations, the 844ins 68 of cystathionine b-synthase and $\mathrm{A}(2756) \mathrm{G}$ of methionine synthase, with lowered plasma homocysteine levels. Atherosclerosis 149: 131-137. http://dx.doi.org/10.1016/S0021-9150(99)00297-X

van Stralen KJ, Le Cessie S, Rosendaal FR and Doggen CJM (2007). Regular sports activities decrease the risk of venous thrombosis. J. Thromb. Haemost. 5: 2186-2192. http://dx.doi.org/10.1111/j.1538-7836.2007.02732.x

Varga EA, Sturm AC, Misita CP and Moll S (2005). Cardiology patient pages. Homocysteine and MTHFR mutations: relation to thrombosis and coronary artery disease. Circulation 111: e289-e293. http://dx.doi.org/10.1161/01. CIR.0000165142.37711.E7

Vuckovic BA, Cabarkapa VS, Ilic TA, Salatic IR, et al. (2013). Clinical significance of determining plasma homocysteine: case-control study on arterial and venous thrombotic patients. Croat. Med. J. 54: 480-488. http://dx.doi.org/10.3325/ cmj.2013.54.480

Weisberg I, Tran P, Christensen B, Sibani S, et al. (1998). A second genetic polymorphism in methylenetetrahydrofolate reductase (MTHFR) associated with decreased enzyme activity. Mol. Genet. Metab. 64: 169-172. http://dx.doi. org/10.1006/mgme.1998.2714

Lazo-Langner A, Squizzato A and Ageno W (2011). Retinal-vein occlusion. N. Engl. J. Med. 364: 979, author reply 979. http://dx.doi.org/10.1056/NEJMc1014381

Wu Y, Tomon M and Sumino K (2001). Methylenetetrahydrofolate reductase gene polymorphism and ischemic stroke: sex difference in Japanese. Kobe J. Med. Sci. 47: 255-262.

Yakub M, Moti N, Parveen S, Chaudhry B, et al. (2012). Polymorphisms in MTHFR, MS and CBS genes and homocysteine levels in a Pakistani population. PLoS One 7: e33222. http://dx.doi.org/10.1371/journal.pone.0033222

Genetics and Molecular Research 16 (1): gmr16019374 
Yi P, Pogribny I and Jill James S (2002). Multiplex PCR for simultaneous detection of 677 C-->T and 1298 A-->C polymorphisms in methylenetetrahydrofolate reductase gene for population studies of cancer risk. Cancer Lett. 181: 209-213.http://dx.doi.org/10.1016/S0304-3835(02)00060-5

Zhang G and Dai C (2001). Gene polymorphisms of homocysteine metabolism-related enzymes in Chinese patients with occlusive coronary artery or cerebral vascular diseases. Thromb. Res. 104: 187-195. http://dx.doi.org/10.1016/ $\underline{\text { S0049-3848(01)00352-8 }}$

\section{Supplementary material}

Table S1. Primer sequences and restriction enzymes used in the analysis of polymorphisms of MTHFR and CBS genes.

Genetics and Molecular Research 16 (1): gmr16019374 